(2) Open Access Full Text Article

\title{
Genetic privacy and the use of archival human material in genetic studies - current perspectives
}

This article was published in the following Dove Press journal:

Medicolegal and Bioethics

25 June 2015

Number of times this article has been viewed

\section{Gareth Jones}

Department of Anatomy, University of Otago, Dunedin, New Zealand
Correspondence: D Gareth Jones Department of Anatomy, University of Otago, PO Box 913, Dunedin 9054, New Zealand Email gareth.jones@otago.ac.nz
Abstract: There has been considerable debate over a number of years on the ethical issues raised by the research uses to which archival human material can be put. Material of this nature has fitted into two categories: tissue in pathological collections and museums, and tissue removed at surgical operations. Considerable emphasis has been placed on whether the material is anonymous or whether it can be/has been de-identified or anonymized. These have emerged as of considerable significance for the role and nature of informed consent under a variety of circumstances. A guiding principle has been the protection of the donor's privacy. Debate on the use of archival material has raised the question of the relationship between it and the subjects from whom it came. Much of the debate was prompted by various retained organs scandals that came to light in the 1990s. The uncertainty underlying many of these deliberations was exposed when attention turned to genetic analyses. Discussions of the uses of archival material for genetic studies have proceeded for well over 20 years as it was realized that genetic information has the potential to provide increasing amounts of information about an individual's (and their family's) likely future, particularly in terms of physical and mental well-being. It was also becoming apparent that there is increasing tension between the relative benefits of the research project for medicine and risks to participants' privacy. These considerations took on added dimensions when the spotlight turned onto the family of Henrietta Lacks and the HeLa cell lines, prompted by publication of the sequencing of the genome of HeLa cells. What became obvious was that much of the work on HeLa cells over a period of 60 years had taken little account of the wishes or privacy of the family, thereby abrogating fundamental ethical values that had been gradually emerging in other discussions on archival human material. The scene was now set for finding more satisfactory ways forward, while acknowledging the complex dimensions of consent, confidentiality, privacy, exploitation, and anonymity in the genetic arena. In responding to these developments, the ways in which genetic privacy can be protected are discussed, alongside querying whether this will continue to be feasible in future alongside the increasing capabilities of genetic technology.

Keywords: HeLa cell lines, Henrietta Lacks, informed consent, ethical values, pathological collections, anonymized tissue

\section{Case study - HeLa cell line}

Issues of genetic privacy came to a head with the publication of Rebecca Skloot's book The Immortal Life of Henrietta Lacks in 2010, ${ }^{1}$ in which she brought to the attention of a worldwide public "the interplay of race, poverty, science and one of the most important discoveries of the last 100 years." ${ }^{2}$ Many of the features of the story of HeLa cells are well known, as is their extraordinary value to scientific research. However, their illustrious progeny in the laboratory cannot hide the tortuous depths 
of the ethical and legal questions that come with them. And yet these were hidden or overlooked for many years.

It was in 1951 that a biopsy of a cancerous cervical tumor was taken from Henrietta Lacks, a working-class AfricanAmerican woman living near Baltimore, MD, USA. ${ }^{3}$ The cells were taken without her consent or even knowledge; neither was her family consulted. This marked the beginning of the immortal HeLa cell line, the first human cells to be grown successfully in the laboratory. In the early 1950s, no one could have foreseen how useful these cells were to become for medicine - with contributions to the development of the polio vaccine, in vitro fertilization, the discovery of human telomerase, roles in gene-expression experiments, and so on. It is estimated that up to 75,000 papers have utilized HeLa cells.

While this way of acting was not considered amiss in the ethical climate of the early 1950 s, it inevitably raises a host of ethical queries for contemporary commentators. However, more was to come. In 1971, the journal Obstetrics and Gynecology named Henrietta Lacks (who died aged 31 years in 1951) as the source of the HeLa cells, thereby shattering the privacy of her family - again without consent. It was not until 1973 that the family learned about HeLa cells, when scientists approached her family members to collect blood to map HeLa genes. Yet again, there was no satisfactory informed consent. At around this time, the Lacks' family medical records were released to the press without their consent. ${ }^{4}$ Much later, in 1996, the Lacks family was honored at the first annual HeLa Cancer Control Symposium that had been organized by a scientist who isolated HeLa cells. Even though Skloot, in 2010, had published a great deal of the background, the publication of the HeLa genome in 2013 occurred initially without the family's knowledge.

This series of events was to prove revolutionary for genetic privacy and the use of archival human tissue. While the earlier events were conducted in accordance with the ethical expectations of the time, the violation of the family's privacy by publishing Henrietta's medical records and the family's genetic information points at the best to carelessness on the part of journalists and researchers and at the worst to an appalling lack of consideration for a family and their interests. ${ }^{5}$ This demonstrates the huge gulf that has existed between the person and her interests (including those of her descendants) and a cell line of intense scientific interest and value. A dissociation of this order is not unknown in biomedical research. For instance, in the dissection of dead human bodies, there is tension between obtaining them ethically and in the most favorable condition for scientific research.
This came to the fore in the 1930s and 1940s in Nazi Germany and its occupied territories, when bodies were obtained to order from extermination camps shortly after execution., There is no suggestion that unscrupulous activity of this magnitude had occurred in relation to the use of HeLa cells, but when no connection exists between the human dimensions surrounding the source of the tissue and the resulting science, little room is left for ethical drivers.

Before continuing with the HeLa account, it will be helpful to sketch the background discussion on the ethical values that have emerged as central to the use of archival human material.

\section{Nongenetic archival material - ethical values}

While the issues raised by the ability to elicit genetic information from stored human tissue take ethical debate into new territory, the background is provided by the longer standing debates on the uses of archival (stored) human tissue. The tissue in this case falls into two categories - that obtained at postmortem, and surplus tissue resulting from surgical operations. The broad framework enunciated in both instances sets the scene for the more complex genetic debate.

\section{Tissue in pathological collections and museums}

The term "archival" covers the long-term preservation of tissue or organs, ${ }^{8}$ although it may also refer to pathological archives of histological slides, including blood stains. ${ }^{9}$ Material is designated as archival as soon as it is kept for future reference, when it is no longer needed to establish the cause of death; it is now surplus to the requirements of medical diagnosis. ${ }^{10}$ The goal of pathological archives is to enhance medical understanding.

A concept frequently encountered in this context is that of anonymity. As the name suggests, this refers to unidentified specimens, which cannot be linked to any identifiable individual. Such specimens are of value in contributing to an understanding of diseases, and therefore do not need to be linked in any specific way to known individuals. Closely related to "anonymous" is the concept of "anonymized"; in this instance, the specimen from a known individual becomes anonymous by removing any means by which it could be linked back to that individual. ${ }^{11,12}$

Museum archives are chiefly made up of anonymous archival material, the earliest of which is considered to be historic archival material. In the UK, material is classed as 
historic either prior to $1970^{13}$ or 1961 , before which there were no regulations regarding organ retention following postmortem. ${ }^{14}$ Historic archival material cannot be linked to known individuals, and it is not known whether consent was obtained, nor how the material was obtained in the first instance. ${ }^{15}$

In the UK, the Retained Organs Commission stated that "the views of family members and the historic and educational value of the collections needs to be considered before decisions are taken on retention or disposal". ${ }^{14}$ What emerges here is the importance of treating the material with respect, while any use of the material today is to conform to contemporary ethical attitudes and values.

In opposition to this approach is that of the National Bioethics Advisory Commission ${ }^{11}$ in the United States, with its conclusion that anonymous or anonymized specimens are not to be classed as research with human subjects. On this basis, there is no place for informed consent; neither is ethics review required. This conclusion was reached by separating the existing archival material from any living human individuals, leading to the view that there can be no risk to the original donor(s). ${ }^{12}$ A driving concern of the commission was to capitalize on the research potential of all stored anonymous tissue. Others have expressed a similar viewpoint ${ }^{16}$ stemming from concerns about undue emphasis upon the protection of privacy and autonomy leading to what they regard as an excessive desire to control the use of human organs and tissues. From their perspective, a failure to distinguish samples from persons could encourage reductionism at the expense of individual integrity.

According to the Royal College of Physicians, ${ }^{10}$ research on archival material is ethical even when there has been no consent on the part of individual patients, as long as certain provisos are adhered to. These include early anonymization of the material, that subjects are not to be inconvenienced, and that, in the face of any doubt about the intrusive nature of the research, consent is obtained. If there is no possible way of linking the material to patients (anonymous archival material), these provisos do not apply, since in that case, no harm can be done to a known person or their family. In this circumstance, there is no threat to the subject's privacy and they are not being treated as a means to an end. ${ }^{17}$ Once again, there is an attempt to balance potential harms to a living individual against postulated restrictions (harms) to the future development of scientific understanding and medical competence. The argument tends to be that the threats to existing individuals by the use of anonymous archival human material are small compared with the benefits that may accrue for medicine and the well-being of future patients.

Identifiable tissue presents a different series of challenges. Should this be anonymized (de-identified) as soon as the immediate uses for which it was collected have been completed? This material was first collected with consent for specific purposes. On this basis, anonymization can be justified if the initial consent included agreement to later anonymization in order to undertake research. Straightforward as this sounds, it is anything other than straightforward. This is because the nature of any future research may be unclear or unknown, while it could be used for commercial purposes, or there may emerge cogent grounds for wishing to link it back to the donor from whom it was derived. A form of broad consent may cover these possible uses, but the implications of giving broad consent need to be explained to the prospective donor. Only in this way will the autonomy of that individual be respected.

From this it follows that the availability of archival material represents a compromise position that should not be used in such a way that it demeans the respect given to human beings and any tissue derived from them. ${ }^{18}$ Routinely, it is preferable to strive for consent if at all possible, with its basis in altruism and a gift relationship. ${ }^{14}$ Inevitably, this cannot occur when presented with anonymous archival material. ${ }^{19}$ Despite this, an ideal is to seek to treat archival samples with the same level of care and respect one would show donated material. ${ }^{15}$ This, in turn, requires an attitude that sees those with oversight of the material as custodians and not owners of it, ${ }^{19}$ leading to a commitment to store this material safely and ensure that it is used in high-quality, medically valuable research.

The relationship between the individual from whom material was originally derived and the uses to which the now anonymized material will be put has led to the notion that there should be separation between the two in order to protect the privacy of the individual. However, is this an impractical ideal, and indeed is it even an ideal? Is severance ever complete, an issue that arises with urgency when genetic studies are envisaged? Some express the conundrum in different terms, arguing that severance should never be complete on the grounds that there will arise situations where linking the data to the patient and their family may serve the interests of the family. If analysis of tissue reveals the existence of a hereditary condition that is not currently suspected and would not become evident for some time, the ability to link the tissue to the individual from whom it came may well serve their interests. To ignore this possibility on the ground 
of maintaining rigid separation of tissue and individual is to make anonymization into an ethical shibboleth.

Beyond this, linkage may also serve the interests of science. Unfortunately, connections between existing material and human interests can be abrogated as brought to light by the plethora of retained organs and body parts scandal in various countries. ${ }^{20-24}$ While a great deal was learned from these scandals, and one hopes similar events will not be reenacted in future, they serve as a salutary lesson that human tissue and the people from whom this tissue came do not occupy distinct compartments, either conceptually or in practice. Investigation of human tissue is of more than scientific interest, even when anonymity can be guaranteed. Was it obtained ethically in the first instance, and is it being studied ethically in the present? From this it emerges that "absolute" anonymization is open to exploiting the interests of individuals rather than protecting them and their legitimate interests.

\section{Tissue removed at surgical operations}

Values that emerge repeatedly in this domain are those of donor consent, protection of donor privacy, and the support of research using human tissue. ${ }^{25}$ While the consent of the patient (research participant) occupies a position of supreme ethical and social significance, the extent and nature of consent are more difficult to delineate. It is not the intention of this review to analyze tissue guidelines from a range of jurisdictions in detail, but it is worth commenting that there is frequently lack of clarity as to the precise dimensions of the consent required when examining guidelines from jurisdictions such as the UK, Iceland, Estonia, USA, or Germany.

Consent tends to be classified in a number of ways, from specific consent to broad consent. Specific consent seeks to provide patients with the option of agreeing to one specific project. By contrast, broad consent, as its name implies, covers a broad swath of projects that satisfy criteria set by the curators of the facility where the tissue is stored. Besides these forms of consent, a third option is represented by tiered consent, where patients are provided with a list of choices, ranging from one identified project to research use in general. For instance, the identified project may be analysis of the tissue removed at operation, say, a gallbladder, in order to gain increased understanding into the formation of gallstones. ${ }^{25}$ Beyond this project of immediate relevance to this patient and others like her, some cells could be used to study a particular hormone produced by gallbladders and other organs. A third project using the gallbladder tissue is a genetic one, in which it is discovered that the sequence of a gene works differently in people prone to gallstones. Specific consent would only have permitted the first project. Broad consent would automatically approve of all three and of many others even further removed from the rationale for the original project. Tiered consent would cover these three projects, as long as there was a consistent theme running through all three, even though the latter two would not have been foreseen at the time of the operation and the availability of the gallbladder tissue.

A final option is that of no consent, where the donors cannot be identified. This approach may include a requirement for de-identification of the tissue sample and associated records. In addition, patients may be presumed to have consented to research use of the tissue unless and until they make it known that they do not consent. These positions are derived from the stances taken by a variety of legislatures. ${ }^{19,26-29}$

This diversity reveals tensions between the various principles that underlie the regulation of research using surplus clinical tissue. For example, Salvaterra et al assert that "Broad consent is not truly informed consent, but rather is a generic authorisation that sacrifices the right of the donor to self-determination in favour of research interests." 30 Against this, Hansson et al point out that "[a]cceptance of broad consent and future consent implies a greater concern for autonomy than if such consents are prohibited." ${ }^{31}$ Yet both broad and specific consents are presented (although by different authors) as ethical approaches to the tension inherent in the individual and public interests created by the research use of tissue.

Anonymization (de-identification) has much the same rationale here as in the case of pathological museum specimens. Removal of identifying information means that researchers cannot link the tissue or associated medical records to a specific patient. This is specified as a means of protecting donors from harm arising from breaches of their privacy. In practice, there are limitations to the removal of information from a record or sample if it is to be made fully anonymous. Hence, the term "anonymization" is not entirely accurate, although it (or de-identification) is sometimes presented as an alternative to withdrawing the tissue entirely from research use. ${ }^{21}$

The practical problems encountered in undertaking studies on archival human material, even where no genetic studies are envisaged, have begun to indicate that the concept of anonymization is not a foolproof way of protecting the privacy of research participants. While it has proved useful and is not to be dismissed as of no value, it cannot be relied upon to protect individuals under all circumstances. 
One of the problems is that tissue samples can be preserved for long periods of time, while research questions impossible to address today may be feasible in 10-20 years' time. This means that it may be impossible to predict the precise research question to be asked or the protocol to be used a few years hence. Consequently, current consent will have to be phrased very broadly, ${ }^{32-34}$ or the patient will have to be recontacted whenever there is a protocol change. ${ }^{31}$ Both have serious drawbacks, in terms of feasibility or downplaying the autonomy of the donors. ${ }^{35}$

The introduction of a future dimension transforms the character of consent since the informed aspect of it is diluted (how can a patient consent in an informed manner to something the scope of which is unknown?). When a genetic element is added to this mix, there is not only a future dimension but also a past/community (family) one. This immediately casts doubt on notions of privacy and autonomy - for close family members as well as the one from whom the tissue has come. The advent of increasingly powerful genetic techniques was to expose these limitations all too forcefully.

\section{Use of archival material for genetic studies - early work}

As has just been outlined, publications from the pre-HeLa debate provide some indication of the ethical principles considered to be relevant in this broader context. While these discussions proved very helpful in terms of the retention of organs and body parts following postmortems, genetic considerations did not enter the picture. Around this time, court cases in the United States in the 1990s and early $2000 \mathrm{~s}^{36,37}$ underscored the principle of respect for human persons, and hence the role of informed consent when collecting tissue samples from them. From this it follows that they are to have a say in the intended uses of their biological materials. ${ }^{38}$ However, the courts reasoned that research products derived from a sample are distinct from the original tissue. In their view, there is a conceptual and ethical gap between the samples and the individual from whom the sample came. As soon as the implications of genetic analyses are taken into account, it is doubtful whether this separation is as convincing as suggested.

Once this happens, there are implications for the nature and character of informed consent. The incentive to examine existing regulations was driven by the ethical imperative to protect human subjects within an environment that encouraged and facilitated genetic research on human tissue. To this end, a number of analyses and sets of recommendations appeared in the mid-1990s. ${ }^{39-41}$
The set of recommendations advocated by Clayton et a ${ }^{39}$ represented the outcome of a workshop convened by the National Institutes of Health (NIH) and Centers for Disease Control and Prevention (CDC) and was anticipating the challenges that would be presented for adequately informed consent in the future. They were therefore seeking to prepare for future innovations that they could see would have ethical repercussions. The bottom line for these recommendations was the requirement for informed consent, using linkable samples unless there were sufficient conditions for a limitation or waiver. However, when existing samples are anonymous at the time the research begins, it was concluded that informed consent is not needed for genetic studies if identifiers are irretrievably removed. While there were differences of opinion on the need for consent to anonymize samples already in existence, the weight of opinion veered toward seeking consent. However, two considerations emerged at this point: the ethical acceptability or non-acceptability of recontacting those from whom the samples had come, and the benefits of being able to determine the genetic determinants of the family's disorder.

The discussions that informed these recommendations had much in common with more general discussions on the research uses of human tissue, even though the latter did not take genetic considerations into account. This probably reflected the state of the genetic literature of the time, something that has changed quite profoundly in the subsequent 20 years.

The position represented by this NIH/CDC Working Group, as well as that of the US Genetic Privacy Act ${ }^{40}$ has been criticized by some writers ${ }^{42}$ as being too stringent in that it views genetic information as being qualitatively different from other forms of personal information and consequently requires special protection. The differences between commentators revolve around the manner in which they seek to balance the interests of individual privacy and the potential benefits of research. ${ }^{42}$ However, the Genetic Privacy Act was prescient in realizing three developments. The first is that genetic information is both powerful and personal, so that in the future genetic analyses will provide increasing insights into a person's likely future. The second is that the act of deciphering a person's genetic code provides probabilistic health information about their family. Third, "the DNA molecule can become the source of an increasing amount of information as more is learned about how to read the genetic code." ${ }^{40}$

One could argue that its precautionary stance was appropriate, as demonstrated subsequently by the HeLa 
cells debate, although, undoubtedly, details of the extent of written authorization, and the degree to which the donors retain destruction rights over the sample, will continue to be open to discussion and modification. They may even vary on a case-by-case basis.

The growing tension between the interests of individuals and those of society in the form of increasing genetic understanding of diseases was being increasingly recognized. ${ }^{43}$ Ashburn et $\mathrm{al}^{43}$ realized that issues around confidentiality, consent, and compensation were calling out for a means of achieving a more equitable balance between individual donor protection and societal benefits from tissue-based research. They were poignantly aware of the Icelandic experience with DeCODE Genetics Inc (Reykjavik, Iceland). and the controversy stirred up by efforts to protect individual confidentiality in the face of the increasing ability to relink codes with medical records on the basis of non-identifying information. ${ }^{44-46}$ This has been demonstrated by Gymrek et al, ${ }^{47}$ who were able to discover the identity of a number of individuals on the basis of sequencing their genomes and cross-referencing their data on them with genealogical databases and public records. In this way, they were able to discover the identities of supposedly anonymous research subjects. ${ }^{48}$ In view of these potential problems, Ashburn et al proposed "the establishment of tissue trustees to coordinate the collection, evaluation, storage, and distribution of representative samples of important human diseases at academic medical centres." ${ }^{43}$ A major reason behind this proposal was to ensure that individual trust in the medical community is maintained in an era of burgeoning advances in genetics.

In responding to these issues, Bathe and McGuire ${ }^{49}$ constructed an ethical framework for accessing archival tissues. Their aim was to take account of the needs of the research community alongside the rights and expectations of participants in terms of genetic associations with observable traits. Their emphasis was on genome-wide studies, although it is also relevant to nongenetic biomarker studies using archival tissues.

The principles supporting this framework ${ }^{49}$ are:

- The necessity of balancing the relative benefits of the research project and the risks, including risks to participants' privacy.

- Source data should be coded rather than anonymized.

- If the risks to privacy are assessed as being minimal, a waiver may be possible.

- Assessment of whether risks are minimal should take account of restriction of the databases to bona fide researchers, assessment of the scientific merit of the proposals, and maintenance of participants' confidentiality.

- When there is more than minimal risk, recontact with participants should occur.

- When there is uncertainty regarding the degree of risk to privacy and stigmatization, the precautionary principle points to the need for consent.

- Data from unconsented patients should never be shared in a publicly accessible database.

In formulating this ethical framework, Bathe and McGuire $^{49}$ assessed the meaning of the concept of anonymization when dealing with archival tissue. They recognized that it is a double-edged sword, providing some privacy protection to the individual from which it had been taken at the expense of downgrading the scientific value of the tissue by isolating it from the patient's medical context. They also recognized in 2009 that anonymization is proving increasingly problematic in the genomic era, ${ }^{50-52}$ and hence is an imperfect solution.

In looking at genetic privacy, Bathe and $\mathrm{McGuire}^{49}$ opt for a pragmatic perspective, highlighting genetic antidiscrimination rather than genetic privacy. This seeks protection against the misuse of genetic information to avoid potential harms, such as various forms of discrimination based on ethnicity or mental illness. It accepts that genetic privacy cannot be assured, although concerted efforts should be made to protect donors from harm. Protection of this order applies not merely to individuals, but also to small populations such as that found in Iceland. ${ }^{53-55}$ Potential stigmatization is a clearly identified possibility, and efforts to avert it demand what some have referred to as a prudent approach. ${ }^{56,57}$

Informed consent, based on the value of autonomy, takes on multifaceted dimensions in the face of using archival tissue, since it could include attempts to recontact patients or their families. Even this may represent an intrusion of privacy, especially if the donor has died. ${ }^{58}$ Some are concerned that if there are many refusals, there may be selection bias, ${ }^{58,59}$ while others contend that the value of research using this material for medicine in the future outweighs attempts to obtain consent. ${ }^{60}$ However, this latter option is a direct threat to patients' autonomy, and any move in this direction is suboptimal, ${ }^{1}$ and has intriguing similarity to the use of unclaimed bodies in anatomical teaching and research. ${ }^{7}$

The likelihood of using tissue without consent is regarded by some commentators as potentially stigmatizing, and retraces the debate over the way in which samples from the Havasupai tribe collected for diabetes research were subsequently used for other disease conditions, including 
schizophrenia and inbreeding. ${ }^{61}$ In that case, consent should have been obtained because of the potential for using the data to elicit information on an identifiable population for purposes other than the stated reasons for obtaining it and in ways that could have had serious cultural repercussions for the group.

It is into this melee that yet another term has entered the literature: "pseudonymization". ${ }^{62}$ Unlike anonymization, where all connections with the individual are removed, pseudonymization involves the use of pseudonyms to replace most identifying fields. Examples might be an NHS number or equivalent, date of birth, postal code, or year of birth. The legitimacy of proceeding in this manner is hotly contested, especially in connection with the 100,000 Genomes Project. ${ }^{63}$ The issues are reminiscent of some of the preceding debates over future uses of genomic information, where the trustworthiness of the authorities with access to the data and the transparency of the projects become central. This is perhaps a key to the way forward when dealing with genetic data, with patients being seen more as active participants rather than merely passive providers of essential data (see Use of archival material for genetic studies - contemporary debate).

\section{Use of archival material for genetic studies - contemporary debate}

The scene has now been set for moving to recent developments over the HeLa debate and the broader considerations they raise. It is these considerations that are now being taken seriously following the publication in early 2013 of the sequencing of the genome of HeLa cells, without the family's consent (but once again not breaching any legal restrictions). While this did not abrogate any rules, it demonstrated the inadequacy of the outdated belief that if samples are anonymized, there is no need to obtain consent before using them in research. This is because "anonymity vanishes when it comes to DNA". ${ }^{5}$ Even though it has been claimed that one cannot infer anything about Henrietta Lacks' genome from study of the HeLa genome, others have vigorously contested this and claimed to have demonstrated its falsity. ${ }^{5}$

In March 2013, a team of researchers at the European Molecular Biology Laboratory (EMBL) published a paper: "The genomic and transcriptomic landscape of a HeLa cell line". ${ }^{64}$ The media noted the link to Henrietta Lacks, but this did not elicit any privacy concerns. ${ }^{3}$ Nevertheless, general debate ensued, as attention became focused on the way to attain balance between that which is good for science and medical endeavor and a means of protecting the family's privacy. At last it had become clear that the system was at fault.
This led to the EMBL team removing the data from public access until a resolution was found.

At much the same time, Nature received a manuscript providing a more detailed sequence of the HeLa genome, funded by the NIH. ${ }^{65}$ No privacy concerns were raised by the reviewers. However, these events struck an ethical nerve and led to meetings between Francis Collins, the director of $\mathrm{NIH}$, and members of the Lacks family, and this in turn led to a consensus agreement according to which the data from these and other studies will be available under a controlled access system similar to the NIH dbGaP database, which links individuals' genetic makeup to traits and diseases. The data will only be open to researchers undertaking biomedical research and will be under the control of a committee (HeLa Genome Data Access Working Group at NIH) that includes family members. ${ }^{3}$ The publication of the Adey et $\mathrm{a}^{65}$ paper in Nature complied with these strictures and with Nature's insistence that all data are publicly available online. While these procedures were devised in terms of these particular papers, other NIH-funded researchers who sequence other HeLa cell lines are expected to deposit their data in the dbGaP. ${ }^{66}$ The striking feature here is the emergence of a partnership between the family and the research community, bringing together the interests of both sides of the ethical equation. This surely is a first and hopefully will set a precedent in this increasingly fraught and demanding area.

Significant as this development is, it is far from foolproof. Hudson and Collins ${ }^{66}$ accept that the data already in public databases enable any laboratory, using non-NIH funds, to derive the full sequence and post it on a non-NIH website. The most that can be done at present is to ask researchers to respect the wishes of the Lacks family and to abide by the spirit of the agreement worked out between the family and NIH.

But is this a furor over nothing, as some have contended? ${ }^{67}$ The genome of these cells is not identical to the Lacks' original genome. This is because the cells carry the genetic modifications that led to the formation of the original tumor and that in turn allowed it to grow prolifically. ${ }^{66}$ However, the HeLa genome provides information about the genome of Henrietta Lacks and her family in spite of the changes that have occurred within the HeLa cell line over the years. ${ }^{5}$ The reason is that "the sequence can reveal certain heritable aspects of Lacks' germline DNA, and can thus be used to draw inferences, admittedly of uncertain significance, about her descendants." 66

This agreement is not seen as setting a precedent for other studies, on account of the unique features surrounding the 
long-term identification of Henrietta Lacks. However, there is evidence that it is feasible to identify what are thought to be anonymous participants and their families by linking their genomes with genealogy DNA databases. ${ }^{3,5}$ This, of course, only becomes possible when sufficiently large databases are available.

The recent high-resolution genome sequencing of the "Kyoto" variant of the HeLa cell line follows on from the previous publication of portions of Henrietta Lacks' genetic data, all without family consent. ${ }^{4}$ In this instance, the lack of consent appeared to amount to ignoring the family entirely. While all family members may not feel equally strongly about the need for consent, that is minor compared with the principle at stake. Since the end result may entail divulgence of personal information about many family members, the fallback position should be a protectionist one, with concerns of some family members outweighing the more permissive response of others. If this position is not adopted, publishing genetic data will impinge on the right of the relatives who wish their genetic data to remain private. This assumes there is a right to genetic privacy within families, although there may be no way of ensuring this in practice. This is where understanding and trust become paramount.

Over the past few years, many cell lines have been propagated without donor consent in an era of different ethical expectations; at present, these do not appear to represent substantial invasions of privacy, since they cannot be linked to individuals or family members. However, this is set to change if participants in large genetic projects have also been included in genetic genealogy analyses with their data available in shared databases. ${ }^{4}$ These possibilities challenge policy positions at a number of junctures, pointing to a need to balance the stringency of regulations, the prospects for ongoing biomedical research, and the privacy of family members.

The major ethical lesson to be learned from the HeLa episode is the absence of consent requirements for research in this genetic domain. It is still possible, at least in the United States, to use specimens and generate whole genome sequencing data without either the knowledge or permission of those providing the sample, on condition that the sample has been "de-identified". However, while this has been regarded as a bastion of protection for human research subjects, it is becoming increasingly evident that it is somewhat "illusory". ${ }^{66}$ As previously discussed, this results from technological advances in genomics and computing. ${ }^{47,50,52,68}$

The solution does not appear to rely completely on any one notion of consent, in isolation of the context within which the research has been conducted. A step in this direction is to regard participants as partners and not simply subjects. ${ }^{66}$ Within this framework, their views will be sought and every effort will be made to explain the ramifications of the research, including the areas where there are substantial unknowns. The latter are particularly evident with future research possibilities. While participants may frequently have limited understanding of the research, attempts to keep them informed are the outcome of basic educational imperatives.

There is no escape from the issue of privacy in the genetic arena, but excessive emphasis on privacy may curtail the public benefit that could arise from further scientific research. This tension is set to increase exponentially as more and more data are generated by large epidemiological and cohort studies that track people's health over many years. ${ }^{69}$ Genomic data linked to large sets of patients' records may reveal insights into diseases difficult to obtain in any other way. This is where the perplexity of ethical analysis comes into play. One imperative is to maximize the value of research data from human patients, whereas an apparently contradictory imperative is to protect the interests of individuals. This is exactly where the HeLa dilemma comes into play. How will the specific data access procedures, developed for HeLa cells, be implemented on a broader scale?

\section{Conclusion}

While the HeLa debate appeared to come out of nowhere, this review demonstrates that it was but a further development in ongoing thinking about which ethical values are most applicable to conducting research on archival human material. The interesting feature of these debates is that while some of them engaged with values such as informed consent, exploitation, anonymity, and privacy, others paid far less attention to them. Not only this, concepts such as consent and anonymity emerge as being far from straightforward even when no account is taken of genetic factors. It should come as no surprise, therefore, that the issues raised by the HeLa debate and the welfare of the Lacks family are demanding for both scientists and ethicists.

Although the term "genetic privacy" has been extensively used in the present context, this notion itself demands further analysis. The rapid developments in genetic analyses that go far beyond present knowledge and understanding will present formidable challenges for the protection of human subjects, since a wealth of personal information will be obtainable from tissue samples. How we cope with these challenges will tax our ethical systems, as we are forced to ask profound 
questions at the interface of science and society. How far will society wish these investigations to proceed? To what extent are they likely to reduce the burden of disease or add to fears of excessive control over human health and well-being? Perhaps the term "genetic privacy" is itself a misnomer.

\section{Disclosure}

The author reports no conflicts of interest in this work. He writes as an academic employed part-time by the University of Otago, Dunedin, New Zealand.

\section{References}

1. Skloot R. The Immortal Life of Henrietta Lacks. New York: Crown Publishers; 2010.

2. Margonelli L. Eternal life. The New York Times. February 7, 2010.

3. Callaway E. Deal done over HeLa cell line. Nature. 2013;500: 132-133.

4. Entine J. Your DNA in death: reflections on the Henrietta Lacks bioethics controversy [webpage on the Internet]. Genetic Literacy Project; 2013. Available from: http://geneticliteracyproject.org/2013/04/01/your-dnain-death-reflections-on-the-henrietta-lacks-bioethics-controversy/. Accessed February 10, 2015.

5. Skloot R. The immortal life of Henrietta Lacks, the sequel. The New York Times. March 23, 2013. Available from: http://www.nytimes. com/2013/03/24/opinion/sunday/the-immortal-life-of-henrietta-lacksthe-sequel.html. Accessed February 11, 2015.

6. Hildebrandt S. Capital punishment and anatomy: history and ethics of an ongoing association. Clin Anat. 2008;21:5-14.

7. Jones DG, Whitaker MI. Anatomy's use of unclaimed bodies: reasons against continued dependence on an ethically dubious practice. Clin Anat. 2012;25:246-254.

8. Royal College of Pathologists. Guidelines for the Retention of Tissue and Organs at Post-mortem Examination. London: Royal College of Pathologists; 2000.

9. Nuffield Council on Bioethics. Human Tissue: Ethical and Legal Issues. London: Nuffield Council on Bioethics; 1995.

10. [No authors listed]. Research based on archived information and samples. Recommendations from the Royal College of Physicians Committee on Ethical Issues in Medicine. J R Coll Physicians Lond. 1999;33:264-266.

11. National Bioethics Advisory Commission. Research Involving Human Biological Materials: Ethical Issues and Policy Guidance. Rockville: National Bioethics Advisory Commission; 1999. Available from: https:// bioethicsarchive.georgetown.edu/nbac/. Accessed February 11, 2015.

12. Wertz DC. Archived specimens: a platform for discussion. Community Genet. 1999;2:51-60.

13. Department of Health. Report of a Census of Organs and Tissues Retained by Pathology Services in England. London: Her Majesty's Stationery Office; 2001.

14. Retained Organs Commission. A Consultation Document on Unclaimed and Unidentifiable Organs and Tissue, A Possible Regulatory Framework. London: Retained Organs Commission, National Health Service; 2002.

15. Jones DG, Gear R, Galvin KA. Stored human tissue: an ethical perspective on the fate of anonymous, archival material. J Med Ethics. 2003;29: 343-347.

16. Knoppers BM, Laberge CM. Research and stored tissues. Persons as sources, samples as persons? JAMA. 1995;274:1806-1807.

17. Brady BA. Epidemiological research. In: The Ethics of Biomedical Research: An International Perspective. Oxford: Oxford University Press.

18. Jones DG. Use of bequeathed and unclaimed bodies in the dissecting room. Clin Anat. 1994;7:102-107.
19. Medical Research Council. Human Tissue and Biological Samples for Use in Research. London: Medical Research Council; 2001.

20. Bristol Royal Infirmary Inquiry. Learning from Bristol: The Report of the Public Inquiry into Children's Heart Surgery at the Bristol Royal Infirmary 1984-1995. Bristol: Crown Copyright; 2001.

21. Royal Liverpool Children's Inquiry. The Royal Liverpool Children's Inquiry Report. London: House of Commons; 2001.

22. Jones DG, Galvin KA. Retention of body parts: reflections from anatomy. N Z Med J. 2002;115:267-269.

23. Walker B. Inquiry into the Matters Arising from the Post-Mortem and Anatomical Examination Practices of the Institute of Forensic Medicine. Sydney: The Government of the State of New South Wales; 2001.

24. MacDonald H. Human Remains: Episodes in Human Dissection. Melbourne: Melbourne University Press; 2005.

25. Collie ND. Disclosure or Discourse? Towards a Common Conception of Consent to Research Using Surplus Clinical Tissue [master's thesis]. Dunedin: University of Otago; 2014.

26. German National Ethics Committee (Nationaler Ethikrat). Biobanks for Research. Opinion. German National Ethics Committee; 2004.

27. Ministry of Health. Guidelines for the Use of Human Tissue for Future Unspecified Research Purposes. Wellington: Ministry of Health; 2007.

28. Human Tissue Authority. Code of Practice 1, Consent. London: Human Tissue Authority; 2009 [updated 2014]. Available from: https://www. hta.gov.uk/code-practice-1-consent. Accessed February 23, 2015.

29. OHRP - Guidance on Research Involving Coded Private Information or Biological Specimens [webpage on the Internet]. Rockville: Office for Human Research Protections; 2008. Available from: http://www. hhs.gov/ohrp/policy/cdebiol.html. Accessed October 8, 2012.

30. Salvaterra E, Lecchi L, Giovanelli S, et al. Banking together. A unified model of informed consent for biobanking. EMBO Rep. 2008;9(4):307-313.

31. Hansson MG, Dillner J, Bartram CR, Carlson JA, Helgesson G. Should donors be allowed to give broad consent to future biobank research? Lancet Oncol. 2006;7(3):266-269.

32. Knoppers BM. Biobanking: international norms. J Law Med Ethics. 2005;33:7-14.

33. Wendler D. One-time general consent for research on biological samples. BMJ. 2006;332:544-547.

34. Lipworth W, Irvine R, Morrell B. Consent: a need for guidelines to reflect local considerations. Nature. 2009;461:593.

35. Caulfield T, Kayet J. Broad consent in biobanking: reflections on seemingly insurmountable dilemmas. Med Law Int. 2009;10:85-100.

36. Moore v Regents of the University of California. 51 Cal3d 120, 793 P2d 479,271 Cal Rptr 146 (1990), cert denied, 499 US 936 (1991).

37. Greenberg, 2003 WL 21246347 (so2d, May 29, 2003).

38. Hakimian R, Korn D. Ownership and use of tissue specimens for research. JAMA. 2004;292:2500-2505.

39. Clayton EW, Steinberg KK, Khoury MJ, et al. Informed consent for genetic research on stored tissue samples. JAMA. 1995;274:1786-1792.

40. Annas GJ, Glantz LH, Roche PA. The Genetic Privacy Act and Commentary, Guidelines for Protecting Privacy of Information Stored in Genetic Data Banks, Ethical, Legal and Social Implications of the Human Genome Project. Office of Energy Research, US Department of Energy, No DE-FG02-93ER61626; 1995. Available from: http:// web.ornl.gov/sci/techresources/Human_Genome/resource/privacyact. pdf. Accessed February 23, 2015.

41. Harper PS. Research samples from families with genetic diseases: a proposed code of conduct. BMJ, 1993;306:1391-1394.

42. Korn D. Dangerous intersections. Issues Sci Technol. 1996;13:55-62.

43. Ashburn TT, Wilson SK, Eisenstein BI. Human tissue research in the genomic era of medicine: balancing individual and societal interests. Arch Intern Med. 2000;160:3377-3384.

44. Enserink M. Iceland OKs private health databank. Science. 1999;283:13.

45. Lyall SA. A country unveils its gene pool and debate flares. The New York Times. February 16, 1999;Sect F:1. 
46. Greely HT. Iceland's plan for genomics research: facts and implications. Jurimetrics. 2000;40:153-191.

47. Gymrek M, McGuire AL, Golan D, Halperin E, Erlich Y. Identifying personal genomes by surname inference. Science. 2013;339:321-324.

48. [No authors listed]. Genetic privacy. Nature. 2013;493:451.

49. Bathe OF, McGuire AL. The ethical use of existing samples for genome research. Genet Med. 2009;11:712-715.

50. Lin Z, Owen AB, Altman RB. Genetics. Genomic research and human subject privacy. Science. 2004;305:183.

51. McGuire AL, Gibbs RA. Genetics. No longer de-identified. Science. 2006;312:370-371.

52. Lowrance WW, Collins FS. Ethics. Identifiability in genomic research. Science. 2007;317:600-602.

53. Annas GJ. Rules for research on human genetic variation - lessons from Iceland. N Engl J Med. 2000;342:1830-1833.

54. Angius A, Melis PM, Morelli L, et al. Archival, demographic and genetic studies define a Sardinian sub-isolate as a suitable model for mapping complex traits. Hum Genet. 2001;109:198-209.

55. Markow TA, Martin JF. Inbreeding and developmental stability in a small human population. Ann Hum Biol. 1993;20:389-394.

56. Kriebel D, Tickner J. Reenergizing public health through precaution. Am J Public Health. 2001;91:1351-1355.

57. Charnley G, Elliott ED. Risk versus precaution: environmental law and public health protection. The Environmental Law Reporter. 2002;32: 10363-10366.

58. Hansson MG. Building on relationships of trust in biobank research. J Med Ethics. 2005;31:415-418.

59. Helgesson G, Dillner J, Carlson J, Bartram CR, Hansson MG. Ethical framework for previously collected biobank samples. Nat Biotechnol. 2007;25:973-976.
60. Hansson MG. For the safety and benefit of current and future patients. Pathobiology. 2007;74:198-205.

61. Dalton R. When two tribes go to war. Nature. 2004;430:500-502.

62. Aamot H, Kohl CD, Richter D, Knaup-Gregori P. Pseudonymization of patient identifiers for translational research. BMC Med Inform Decis Mak. 2013;13:75.

63. Hockings E, Coyne L. Privacy and the 100,000 Genome Project. The Guardian. March 10, 2015. Available from: http://www.theguardian. com/science/political-science/2015/mar/10/privacy-and-the-100000genome-project. Accessed March 14, 2015.

64. Landry JJ, Pyl PT, Rausch T, et al. The genomic and transcriptomic landscape of a HeLa cell line. G3 (Bethesda). 2013;3:1213-1224.

65. Adey A, Burton JN, Kitzman JO, et al. The haplotype-resolved genome and epigenome of the aneuploid HeLa cancer cell line. Nature. 2013;500:207-211.

66. Hudson KL, Collins FS. Biospecimen policy: family matters. Nature. 2013;500:141-142.

67. Hughes V. It's time to stop obsessing about the dangers of genetic information. Slate. January 7, 2013 Available from: http://www. slate.com/articles/health_and_science/medical_examiner/2013/01/ ethics_of_genetic_information_whole_genome_sequencing_is_here_ and_we_need.html. Accessed February 12, 2015.

68. Rodriguez LL, Brooks LD, Greenberg JH, Green ED. Research ethics. The complexities of genomic identifiability. Science. 2013;339: 275-276.

69. Bobrow M. Balancing privacy with public benefit. Nature. 2013;500:123.
Medicolegal and Bioethics

\section{Publish your work in this journal}

Medicolegal and Bioethics is an international, peer-reviewed, open access journal exploring the application of law to medical and drug research and practice and the related ethical and moral considerations. The journal is characterized by the rapid reporting of reviews, case reports, guidelines and consensus statements, original research

\section{Dovepress}

and surveys. The manuscript management system is completely online and includes a very quick and fair peer-review system. Visit http://www.dovepress.com/testimonials.php to read real quotes from published authors. 